\title{
Ganoderma lucidum Polysaccharide Enhanced the Antitumor Effects of 5-Fluorouracil against Gastric Cancer through Its Upregulation of NKG2D/MICA
}

\author{
Xi Yang, ${ }^{1}$ Rui Zhang, ${ }^{1}$ Jing Yao, ${ }^{2}$ Chen Xi, ${ }^{1}$ and Shuzhang Du $\mathbb{D}^{1}$ \\ ${ }^{1}$ Department of Pharmacy, The First Affiliated Hospital of Zhengzhou University, Zhengzhou, Henan 450000, China \\ ${ }^{2}$ Jining Medical University, Jining, Shandong 272067, China
}

Correspondence should be addressed to Shuzhang Du; fccdusz@zzu.edu.cn

Received 11 September 2019; Revised 3 November 2019; Accepted 9 November 2019; Published 1 December 2019

Guest Editor: Jianxun Ding

Copyright (๑) 2019 Xi Yang et al. This is an open access article distributed under the Creative Commons Attribution License, which permits unrestricted use, distribution, and reproduction in any medium, provided the original work is properly cited.

\begin{abstract}
5-Fluorouracil $(5-\mathrm{Fu})$ is one of the frequently used first-line cytotoxic drugs for chemotherapy against gastric cancer. Chemotherapy and immunotherapy are currently the main methods for treating gastric cancer. Immunotherapy can enhance the antitumor effect of chemotherapy drugs at the same time reducing its toxicity. The combination of these two therapies to treat cancer has become a mainstay and has received increasing attention in clinical practice. Ganoderma lucidum polysaccharide (GLP) is isolated from the Ganoderma lucidum fruiting body. Studies have shown that GLP has antitumor effects, where GLP does not directly kill tumors, rather exerting its antitumor function by stimulating immune cells including natural killer (NK) cells and T cells. In this study, the antitumor effect of GLP combined with 5-Fu was studied in vivo. At the same time, the associated mechanism of GLP combined with 5-Fu in gastric cancer cell lines BGC823 and SGC7901 was investigated in vitro. The results showed that GLP could stimulate the killing effect of NK-92 cells on gastric cancer cell lines BGC823 and SGC7901 and synergistically enhance the toxic effects of NK-92 cells on gastric cancer cell lines BGC823 and SGC7901. Moreover, GLP could further promote the activity of NK-92 cells by activating the NK cell activating receptor NKG2D and its downstream DAP10/PI3K/ERK signaling pathway.
\end{abstract}

\section{Introduction}

Cytotoxic chemotherapy is an effective treatment for cancer. However, the use of cytotoxic drugs tends to be toxic to normal tissues, affecting the body's hematopoietic function and destroying the body's immune suppression system and easily leads to tumor resistance $[1,2]$. Recently, an increasing amount of attention has been given to the combination use of chemotherapy and immunotherapy which not surprisingly has also been frequently practiced in clinical settings [3]. Not only sustaining the antitumor effect of chemotherapy drugs, immunotherapy can also reduce the immune damage incurred during chemotherapy [4]. The synergistic effects between chemotherapy and immunotherapy have been confirmed in several clinical trials. For example, gemcitabine combined with interleukin-2 has a significant effect in the treatment of metastatic colorectal cancer. In these studies, chemotherapy and immunotherapy synergistically enhanced the presentation of tumor antigens by the immune system and made cytotoxic lymphocytes (CTL) and natural killer (NK) cells more sensitive for tumor cells [5-7].

Ganoderma lucidum belongs to the family Ganoderma lucidum and is a rarified Chinese herbal medicine [8]. Ganoderma lucidum polysaccharides (GLP) are the major active substances of Ganoderma lucidum and have various biological functions, including antitumor [9], immunomodulation $[8,10]$, antioxidation, and hypolipidemic effects [10]. Studies have shown that GLP can inhibit tumor growth in S180 sarcoma-bearing mice and can increase the proportion of CD4 or CD8 T cell subsets in S180 tumor-bearing mice. However, GLP had no cytotoxic effect on S180 cells and PG cells (human lung cancer cells) in vitro. Interestingly, the serum from GLP-treated S180 tumor-bearing mice significantly inhibited the proliferation of S180 cells and PG cells 
in vitro. In addition, GLP can also promote the proliferation of spleen lymphocytes induced by concanavalin A (ConA) or lipopolysaccharide (LPS) and enhance the cytotoxic effects of natural killer $(\mathrm{NK})$ cells and increase the rate of neutral red phagocytosis of macrophages as well. These findings suggested that the antitumor activity of GLP may be mainly associated with the host immune response stimulated by NK cells, T cells, and macrophages [11].

5-Fluorouracil (5-Fu) is a commonly used antimetabolic chemical agent that is widely used clinically in cancer treatment. However, application of 5-Fu can inhibit the immune system and cause leukopenia and atrophy of hematopoietic organs [12-14]. At the same time, 5-Fu also has immunomodulatory effects [15]. And clinically, 5-Fu is often used in combination with cytokines to treat cancer. One of a phase II trial for the treatment of pancreatic cancer with the combination of 5-Fu and Interferon (IFN) showed a 5-year overall survival rate of 55\% [16].

In this study, we explored the antitumor effects and associated mechanism of 5-Fu combined with GLP in vivo. In vitro, GLP directly stimulated NK-92 cytotoxicity by upregulating the expression of NKG2D and activating the downstream DAP10/PI3K/ERK signaling pathway. As for $5-\mathrm{Fu}$, it has been shown to increase and maintain the expression of MHC class I-related molecule A (MHC class I-related china A, MICA) a ligand for NKG2D on gastric cancer cell XXX membrane by inhibiting the expression of ADAM10 (A Disintegrin And Metalloprotease 10) on tumor cells. In summary, the synergistic effect of GLP and 5-Fu enhanced the in vitro toxicity of NK-92 cells to gastric cancer cell lines BGC823 and SGC7901. These results suggested that the combination of GLP and 5-Fu may be a potential strategy for future treatment of gastric cancer.

\section{Material and Methods}

2.1. Material. The Ganoderma lucidum fruiting body was obtained from Changbai Mountain in Jilin Province (Northern elevation $42^{\circ} 35^{\prime}$, longitude $127^{\circ} 54^{\prime}, 731$ meters above sea level). DEAE-52 cellulose and Sephadex G-100 were purchased from Sigma (USA). Fetal bovine serum, DMEM medium, 1640 medium, and trypsin were purchased from Gibco (USA). The reagents used in this study were analytical grade. The human natural killer cell line NK-92 and the gastric cancer cell lines BGC823 and SGC7901 were purchased from the Shanghai Institute of Cell Biology. The CytoTox96 ${ }^{\circledR}$ nonradioactive cytotoxicity assay was purchased from Promega (USA).
2.2. Extraction and Purification of GLP. GLP was extracted with a hot water extraction method [17]. The protein in the crude polysaccharide of Ganoderma lucidum was removed by following the sevag method [18]. The crude GLP from which the protein was removed were separated using a cellulose column (DEAE-52, $1.6 \mathrm{~cm} \mathrm{~d} \times 40 \mathrm{~cm} \mathrm{~h}$ ) to obtain GLP. Distilled water was then used to elute the resulting sample and followed with a gradient of $0.1 \mathrm{M}, 0.2 \mathrm{M}, 0.3 \mathrm{M}$, and $0.4 \mathrm{M}$ sodium chloride solution separately. A Sephadex G100 column $(1.6 \mathrm{~cm} \mathrm{~d} \times 60 \mathrm{~cm} \mathrm{~h})$ was then used to elute the obtained main component at a flow rate of $0.7 \mathrm{ml} / \mathrm{min}$. Following that the phenol-sulfuric acid method was used to measure the concentration of the polysaccharide at $490 \mathrm{~nm}$. The resulting components were then concentrated, dialyzed, and lyophilized to obtain the purified GLP.

2.3. Cell Culture. The human natural killer cell line NK-92 was inoculated into $\alpha$-MEM complete growth medium (DMEM medium was added with $0.2 \mathrm{mM}$ inositol, $0.1 \mathrm{mM}$ 2-mercaptoethanol, $0.02 \mathrm{mM}$ folic acid, $200 \mathrm{U} / \mathrm{ml}$ recombinant IL-2, $12.5 \%$ horse serum, and $12.5 \%$ fetal bovine serum) and cultured in a constant temperature incubator at $37^{\circ} \mathrm{C}$ with $5 \% \mathrm{CO}_{2}$. Cells in the logarithmic growth phase were selected for subsequent experiments.

The gastric cancer cell lines BGC823 and SGC7901 were inoculated into RPMI-1640 medium supplemented with $10 \%$ fetal bovine serum, $100 \mu \mathrm{g} / \mathrm{ml}$ penicillin, and $100 \mu \mathrm{g} / \mathrm{ml}$ streptomycin and cultured in a constant temperature incubator at $37^{\circ} \mathrm{C}$ with $5 \% \mathrm{CO}_{2}$. The growth of tumor cells was monitored under the microscope, and the cells in the logarithmic growth phase were selected for subsequent experiments.

2.4. Measurement of NK Cell Killing Activity. CytoTox96 nonradioactive cytotoxicity assay was used to detect the killing of NK cells against gastric cancer cells. Specifically, PBS was first used to rinse the tumor cells, and a fresh NK-92 medium was used for cell suspension, and finally, the cell suspension was seeded in 96 -well plates with a density of $5 \times 10^{3}$ cells/well. NK-92 cells were then added to 96-well plates at a ratio of $10: 1,5: 1$, and $1: 1$, respectively (NK-92 cells to tumor cell). The 96 -well plates were cultured for $4 \mathrm{~h}$ at $37^{\circ} \mathrm{C}$ in a $5 \% \mathrm{CO}_{2}$ atmosphere, then the supernatant in each well was collected, and the absorbance was measured at $490 \mathrm{~nm}$. The killing effect of NK cells on target cells was evaluated by the following formula:

$$
\% \text { cytotoxicity }=\frac{\text { experiment }- \text { spontaneous effector cell }- \text { spontaneous target cell }}{\text { maximum target cell }- \text { spontaneous target cell }} \times 100
$$

2.5. Measurement of Cell Proliferation with Cell Counting Kit8 (CCK8) Assay. BGC823 and SGC7901 cell suspensions were seeded in 96 -well plates at a density of $5 \times 10^{4}$ cells $/ \mathrm{ml}$,
$100 \mu \mathrm{l}$ per well. The cells were cultured overnight at $37^{\circ} \mathrm{C}$ in a $5 \% \mathrm{CO}_{2}$ incubator. Cells were then given different concentrations of 5-Fu (concentration range: 1-50 $\mu \mathrm{g} / \mathrm{ml}$ ). After 
culturing for $24 \mathrm{~h}, 10 \mu \mathrm{l}$ of CCK8 solution was added to each well, and incubation was continued for another $4 \mathrm{~h}$. The absorbance value of each well was measured at $450 \mathrm{~nm}$ with the microplate reader, and the experiment was repeated 3 times. The survival rate of BGC823 and SGC7901 cells was calculated by the following formula:

$$
\% \text { cell survival }=\frac{\text { Mean value of absorbance in the treatment group }}{\text { Mean value of absorbance in the control group }} \times 100
$$

2.6. Establishment and Administration of BGC823 and SGC7901 Tumor-Bearing Mouse Models. BGC823 and SGC7901 cells $\left(0.1 \mathrm{ml}, 5 \times 10^{6}\right.$ cells $)$ were subcutaneously transplanted into the right ankle of balb/c nude mice. When the tumor grew to $100 \mathrm{~mm}^{3}$, the mice were randomly divided into the following 7 groups, 5-6 mice per group: model group: intraperitoneal injection of saline; three different 5 Fu single groups: $6.25,12.5$, and $25 \mathrm{mg} / \mathrm{kg}$ (intraperitoneal injection of the corresponding 5-Fu drug); combined treatment group: three 5 -Fu drug concentrations $(6.25,12.5$, or $25 \mathrm{mg} / \mathrm{kg}$ ) were combined with $200 \mathrm{mg} / \mathrm{kg}$ GLP for intraperitoneal injection [19]. Tumor size was measured every 3 days for 12 days, and data from day 12 was taken for analysis.

2.7. Detection of NKG2D Protein Expression with FluorescenceCoupled Enzyme-Linked Immunosorbent Assay. NK-92, BGC823, and SGC7901 cell suspensions were seeded in 96well plates at a density of $5 \times 10^{4}$ cells $/ \mathrm{ml}, 100 \mu \mathrm{l}$ per well. The cells were cultured overnight at $37^{\circ} \mathrm{C}$ in a $5 \% \mathrm{CO}_{2}$ incubator. The cells were then given different concentrations of GLP (concentration range: $0-200 \mu \mathrm{g} / \mathrm{ml}$ ). After being cultured for $24 \mathrm{~h}$, the disrupted cells were centrifuged to remove the supernatant, and the expression of NKG2D protein in the cells was detected by fluorescence-coupled enzyme-linked immunosorbent assay.

2.8. Western Blot. NK-92 cell suspensions were seeded in 96well plates at a density of $5 \times 10^{4}$ cells $/ \mathrm{ml}, 100 \mu \mathrm{l}$ per well. The cells were cultured overnight at $37^{\circ} \mathrm{C}$ in a $5 \% \mathrm{CO}_{2}$ incubator. The cells were then given different concentrations of GLP (concentration range: $50-200 \mu \mathrm{g} / \mathrm{ml}$ ). After being cultured for $24 \mathrm{~h}$, cells were collected and total proteins were extracted with the protein lysate. After quantification, proteins were separated by SDS-PAGE and transferred to a PVDF membrane. After blocking for $2 \mathrm{~h}$ at room temperature, 5 different primary antibodies were added and incubated overnight at $4^{\circ} \mathrm{C}$. The primary antibodies were then discarded and the corresponding secondary antibodies were added. After incubation at room temperature for $1 \mathrm{~h}$, the images were developed.

2.9. Statistical Analysis. All data were expressed as means \pm SEM. ANOVA was used to analyze statistical significance between each experimental group.

\section{Results and Discussion}

Chemotherapy along with immunotherapy is one of the current research hotspots in the clinical treatment of cancer. The combination of chemotherapy and immunotherapy not only has a synergistic antitumor effect but can also reduce the immune damage caused by chemotherapy $[20,21] .5-\mathrm{Fu}$ is a widely used chemotherapy drug in clinical settings. Although 5-Fu has immunosuppressive effects, several studies have demonstrated synergistic antitumor effects of 5-Fu when combined with immunomodulators such as IL-12 and IL-15 [21, 22]. The present study investigated the activity and mechanism of GLP combined with 5-Fu for cancer treatment in vitro and in vivo.

3.1. Extraction and Purification of GLP. The deproteinization rate for the crude polysaccharides was $1.5 \%$, and the total sugar content was $27.85 \%$. DEAE-52 cellulose was then used to separate and to obtain two components, DEAE-1 and DEAE-2, with a total sugar content of $58.21 \%$ and $18.96 \%$, respectively. The DEAE-1 fraction having a higher polysaccharide content was further purified with a Sephadex G-100 to obtain GLP with a total sugar content of $75.56 \%$.

3.2. GLP Directly Activated the Antitumor Effects of NK-92 Cells. It is well known that NK cells are an important part of the innate immune system and play an important role in combating cancer [23].

The effects of GLP on the activity of NK-92 cells were determined using the CytoTox96 nonradioactive cytotoxicity assay. As shown in Figure 1(a), NK-92 cells were used as effector cells, and BGC823 gastric cancer cells were used as target cells. The results showed that the killing effects of NK-92 cells on BGC823 gastric cancer cells were enhanced after GLP treatment $(p<0.05)$, and the activity of NK-92 cells reached the highest when GLP was at $400 \mu \mathrm{g} / \mathrm{ml}$, indicating that GLP can directly stimulate the antitumor activity of NK cells in vitro. The results of Figure 1(b) indicated that the $50 \%$ inhibitory concentration (IC50) of 5-Fu against BGC823 and SGC7901 gastric cancer cells was about $50 \mu \mathrm{g} / \mathrm{ml}$ at $24 \mathrm{~h}$. Therefore, in the subsequent experiment, 5 -Fu was used at a concentration of $20 \mu \mathrm{g} / \mathrm{ml}$, which was about half of the IC50 value. GLP was used at a concentration of $400 \mu \mathrm{g} / \mathrm{ml}$.

3.3. GLP and 5-Fu Synergistically Enhanced the Cytotoxic Effects of NK-92 Cells on Tumor Cells. CytoTox96 nonradioactive cytotoxicity assay was used to determine whether GLP combined with 5-Fu can enhance the cytotoxicity of NK-92 cells against BGC823 and SGC7901 cells. NK-92 cells pretreated with GLP $(400 \mu \mathrm{g} / \mathrm{ml}, 24 \mathrm{~h})$ and BGC823 cells or SGC7901 cells pretreated with 5-Fu $(20 \mu \mathrm{g} / \mathrm{ml}, 24 \mathrm{~h})$ were cocultured and compared with the normal control group. 


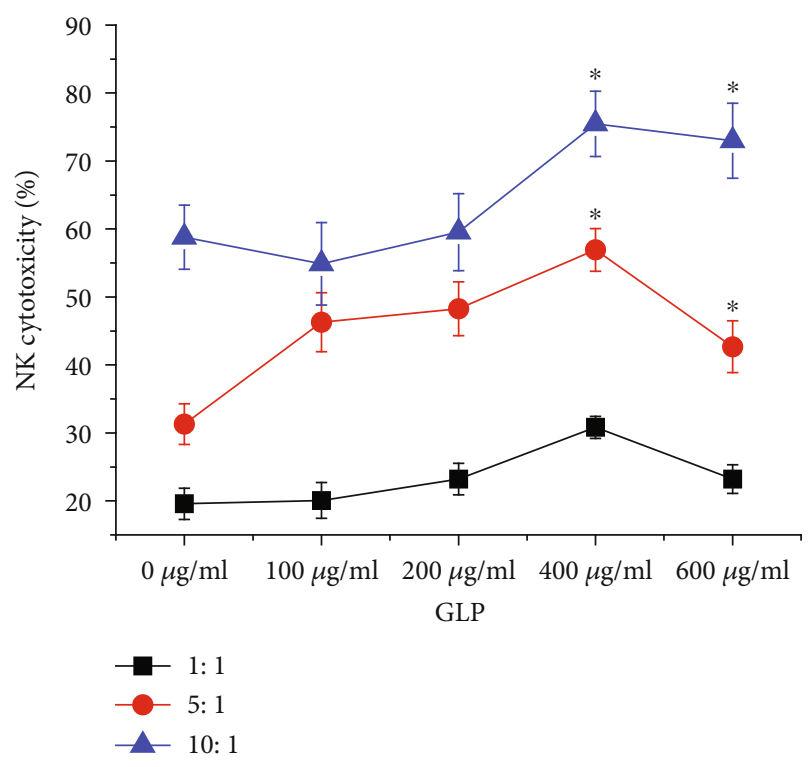

(a)

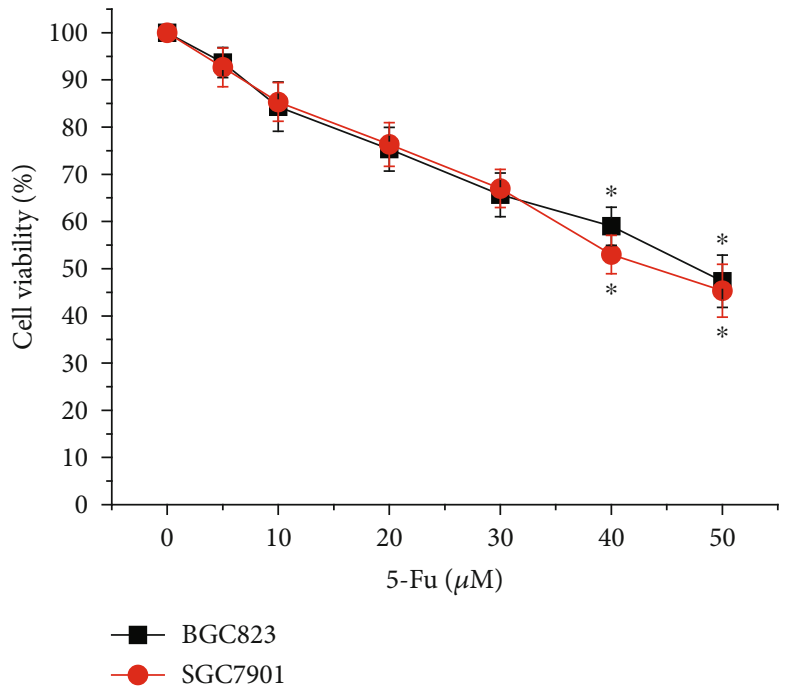

(b)

FIGURE 1: GLP directly enhanced the cytotoxicity of NK-92 cells. (a) GLP increased NK-92 cell cytotoxicity against BGC823 gastric cancer cells in a dose- and ratio-dependent manner. (b) CCK8 cell proliferation assay showed that 5-Fu had cytotoxic effects on BGC823 and SGC7901 gastric cancer cells. Data were expressed as means \pm SEM, and compared with the normal group, ${ }^{*}$ indicated $p<0.05$.

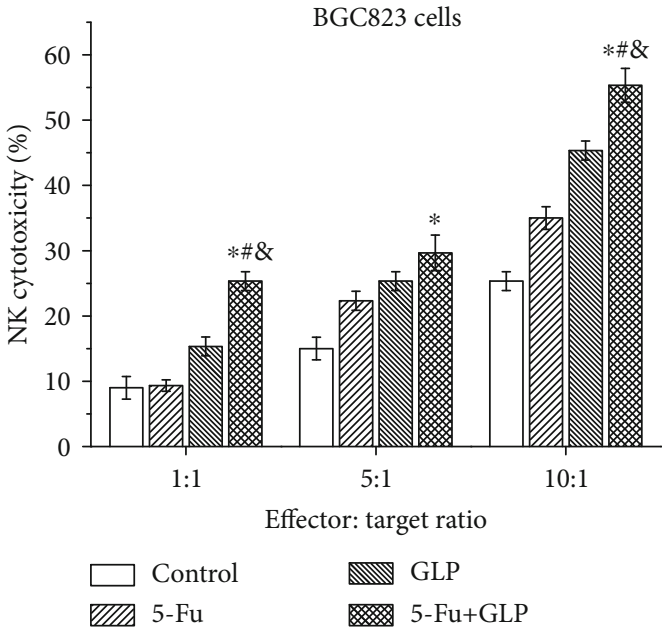

(a)

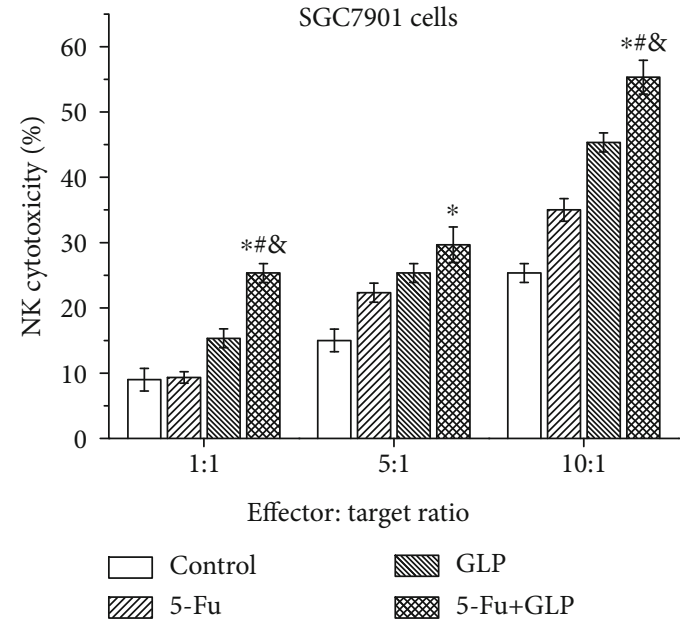

(b)

FIGURE 2: GLP and 5-Fu synergistically enhanced the cytotoxic effect of NK-92 cells on BGC823 gastric cancer cells (a) and SGC7901 gastric cancer cells (b). The data were expressed as means \pm SEM; compared with the control group, ${ }^{*}$ indicated that $p<0.05,{ }^{* *}$ indicated $p<0.05$; compared with the 5-Fu group, ${ }^{\#}$ indicated $p<0.05,{ }^{\# \#}$ indicated $p<0.05$; compared with the GLP group, ${ }^{\&}$ indicated $p<0.05,{ }^{\& \&}$ indicated $p<0.05$.

The results showed that the toxicity of NK cells to both cancer cell lines was significantly enhanced in the cocultured group $(p<0.05$; Figures $2(a)$ and $2(b))$. When the effector-target ratio (E:T) was at $1: 1,5: 1$, and $10: 1$, compared with the 5-Fu group, the toxicity killing rate of NK-92 cells to BGC823 cells in GLP combined with 5-Fu treatment groups increased by $16 \%, 6.33 \%$, and $20.33 \%$, respectively (Figure 2(a)). As for the SGC7901cells, this increase in killing rate was $16.07 \%, 7.06 \%$, and $19.73 \%$, respectively (Figure 2(b)).
3.4. GLP Enhanced the Antitumor Activity of 5-Fu in Gastric Cancer Mice. In vitro, GLP and 5-Fu synergistically stimulated the activity of NK cells to kill tumor cells. By establishing BGC823 and SGC7901 tumor-bearing mouse models, we then explored whether GLP combined with 5-Fu can enhance the antitumor effect exerted by 5 -Fu. The results showed that GLP combined with 5-Fu significantly inhibited the tumor growth in both models compared to 5-Fu alone $(p<0.01$; Figures 3(a) and 3(b)). As shown in Figure 3(a), in the BGC823 gastric cancer cell-bearing mouse model, the 


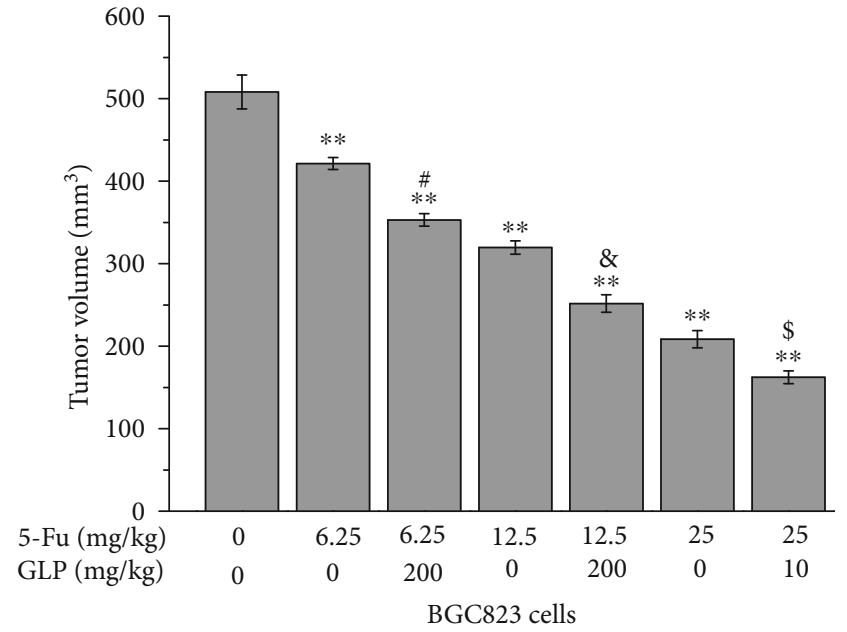

(a)

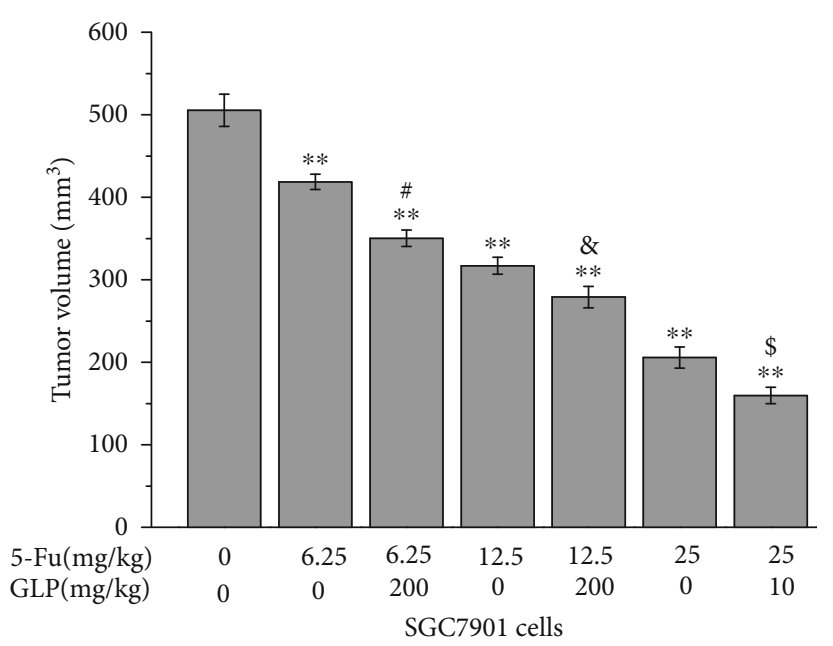

(b)

FIGURE 3: GLP increased the antitumor activity of 5-Fu in gastric cancer-bearing mice. (a) During the treatment of BGC823 gastric cancerbearing mice, GLP enhanced the antitumor activity of 5-Fu at the $12^{\text {th }}$ day of administration. (b) During the treatment of SGC7901 gastric cancer-bearing mice, GLP enhanced the antitumor activity of 5 -Fu at the $12^{\text {th }}$ day of administration. Data were expressed as means \pm SEM; compared with the control group, ${ }^{*}$ indicated $p<0.05,{ }^{* *}$ indicated $p<0.05$; compared with the 5 -Fu $(6.25 \mathrm{mg} / \mathrm{kg})$ group, ${ }^{\#}$ indicated $p<$ $0.05,{ }^{\# \#}$ indicated $p<0.05$; compared with the 5 -Fu $(12.5 \mathrm{mg} / \mathrm{kg})$ group, ${ }^{\&}$ indicated $p<0.05$, \&\& indicated $p<0.05$; compared with the 5-Fu $(25 \mathrm{mg} / \mathrm{kg})$ group, ${ }^{\$}$ indicated $p<0.05$ and ${ }^{\$ \$}$ indicated $p<0.05$.

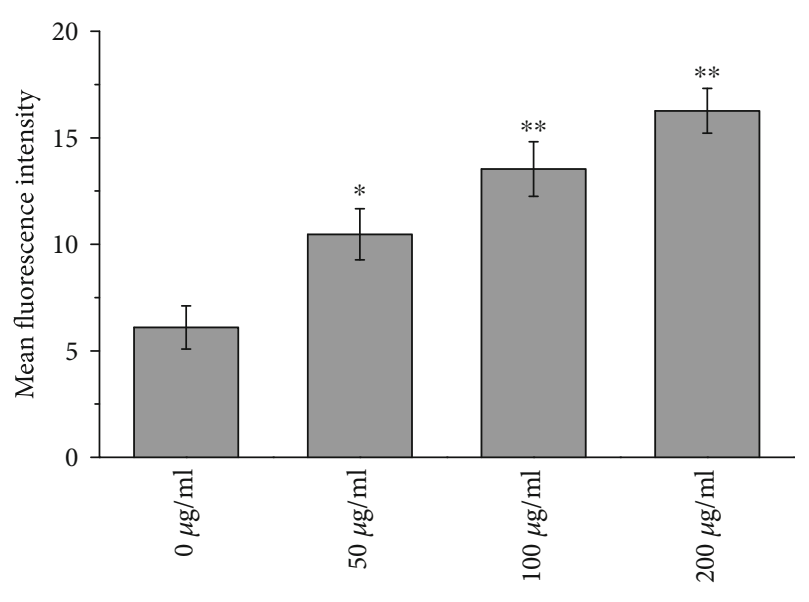

GLP

(a)

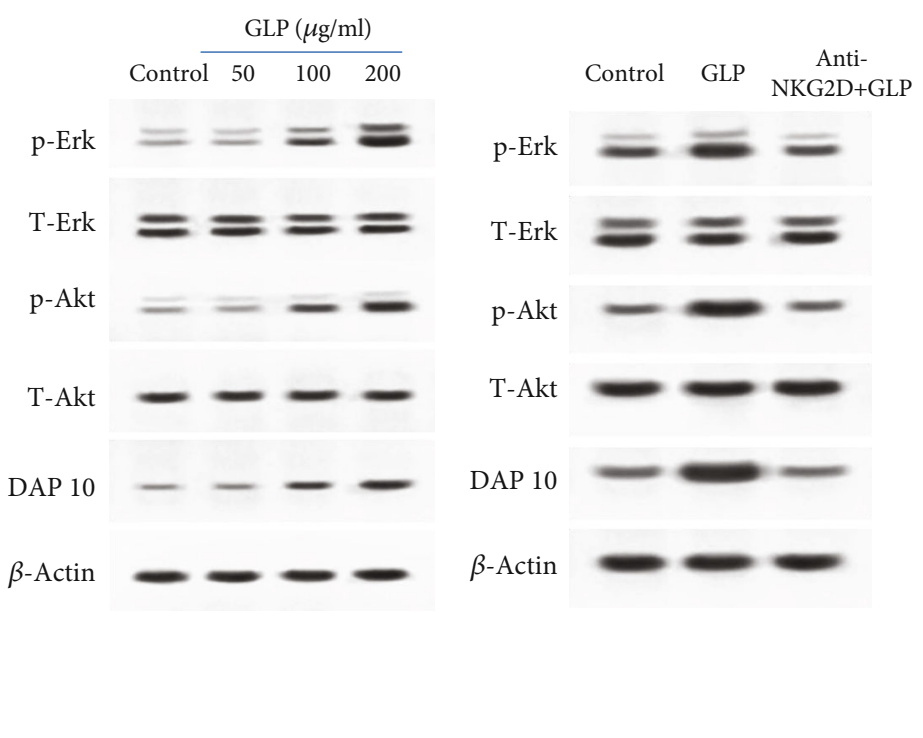

(b) (c)

FIGURE 4: GLP activated NK-92 cells via the NKG2D pathway. (a) GLP enhanced the expression of NKG2D on NK-92 cells in a dosedependent manner. Compared with the untreated group, ${ }^{*}$ indicated $p<0.05,{ }^{* *}$ indicated $p<0.05$. (b) GLP enhanced the phosphorylation levels of Akt and erk and the expression level of DAP10 protein in NK-92 cells. (c) Enhanced phosphorylation level of Akt and erk and the expression level of DAP10 protein in NK-92 cells by GLP treatment were reduced by silencing NKG2D in NK-92 cells with NKG2D antibody.

tumor volume in the combination treatment group was significantly reduced $(p<0.05)$ at the $12^{\text {th }}$ day of administration in comparison to the 5-Fu treatment alone (6.25 or $12.5 \mathrm{mg} / \mathrm{kg}$ : one quarter or half of the highest dose). The tumor inhibition rate reached $68.04 \%$ (Figure 3(a)) when 5$\mathrm{Fu}(12.5 \mathrm{mg} / \mathrm{kg})$ was combined with GLP $(200 \mathrm{mg} / \mathrm{kg})$ as the treatment. Similar results were obtained in SGC7901 tumor-bearing mice. Compared with the 6.25 or $12.5 \mathrm{mg} / \mathrm{kg}$ 5 -Fu treatment group, the tumor volume decreased significantly on the $12^{\text {th }}$ day in the combination treatment group $(p<0.05)$. When $5-\mathrm{Fu}(12.5 \mathrm{mg} / \mathrm{kg})$ was combined with GLP $(10 \mathrm{mg} / \mathrm{kg})$ as the treatment, the tumor inhibition rate reached $68.4 \%$ (Figure $3(\mathrm{~b})$ ). The results showed above indicated that GLP increased the antitumor activity of $5-\mathrm{Fu}$ 
during the treatment of BGC823 and SGC7901 gastric cancer-bearing mice.

3.5. GLP Activated NK-92 Cells via the NKG2D Pathway. Studies have shown that on NK cells NKG2D was expressed as a receptor, whereas phosphatidylinositol-3 kinase (PI3K) is a downstream signaling molecule of NKG2D [24]. Moreover, the PI3K-ERK pathway plays an important role in $\mathrm{NK}$ cell activation and cytotoxicity $[25,26]$. Therefore, the relationship between GLP and NKG2D receptor and its downstream DAP10/PI3K/ERK pathway was verified with ELISA and Western blot.

The results indicated that GLP promoted the expression of NKG2D receptor, as shown in Figure 4(a). The expression of NKG2D was significantly upregulated in NK-92 cells that were treated with GLP compared with the control group $(p<0.05)$. In addition, phosphorylation levels of Akt and erk and expression levels of DAP10 protein were significantly increased in NK-92 cells of the GLP-treated group compared with the control group (Figure 4(b)). After NKG2D was silenced by NKG2D antibody, the phosphorylation levels of Akt and erk and the expression level of DAP10 protein in NK-92 cells of the Anti-NKG2D+GLP group were significantly lower than those treated with GLP alone. And there was no significant difference compared to the control group (Figure 4(c)). These results suggested that GLP may activate the downstream DAP10/PI3K/ERK pathway by upregulating the expression of the NKG2D receptor, resulting in the activation of NK cells.

\section{Conclusion}

Our study showed that GLP not only inhibited tumor growth in gastric cancer cells and gastric cancer-bearing mice but also promoted NK-mediated cytotoxicity. Moreover, GLP may activate the downstream DAP10/PI3K/ERK pathway by promoting the expression of the NKG2D receptor, thus leading to the activation of NK cells. These results revealed the potential efficacy of GLP combined with 5-Fu in the treatment of cancer and further supported the strategy of combining cytotoxic drugs with immunomodulators for effective cancer treatment.

\section{Data Availability}

The data used to support the findings of this study are available from the corresponding author upon request.

\section{Conflicts of Interest}

The authors declare that they have no conflicts of interest.

\section{Acknowledgments}

This work was supported by the First Affiliated Hospital of Zhengzhou University Institutional Youth Fund.

\section{References}

[1] D. Daniel and J. Crawford, "Myelotoxicity from chemotherapy," Seminars in Oncology, vol. 33, no. 1, pp. 74-85, 2006.

[2] V. Tsouris, M. K. Joo, S. H. Kim, I. C. Kwon, and Y. Y. Won, "Nano carriers that enable co-delivery of chemotherapy and RNAi agents for treatment of drug-resistant cancers," Biotechnology Advances, vol. 32, no. 5, pp. 1037-1050, 2014.

[3] L. Apetoh, S. Ladoire, G. Coukos, and F. Ghiringhelli, "Combining immunotherapy and anticancer agents: the right path to achieve cancer cure?," Annals of Oncology, vol. 26, no. 9, pp. 1813-1823, 2015.

[4] V. K. Anagnostou and J. R. Brahmer, "Cancer immunotherapy: a future paradigm shift in the treatment of non-small cell lung cancer," Clinical Cancer Research, vol. 21, no. 5, pp. 976984, 2015.

[5] L. A. Emens and G. Middleton, "The interplay of immunotherapy and chemotherapy: harnessing potential synergies," Cancer Immunology Research, vol. 3, no. 5, pp. 436-443, 2015.

[6] P. Correale, M. G. Cusi, K. Y. Tsang et al., "Chemo-immunotherapy of metastatic colorectal carcinoma with gemcitabine plus FOLFOX 4 followed by subcutaneous granulocyte macrophage colony-stimulating factor and interleukin-2 induces strong immunologic and antitumor activity in metastatic colon cancer patients," Journal of Clinical Oncology, vol. 23, no. 35, pp. 8950-8958, 2005.

[7] K. Pan, Q. Jiang, G. Liu, X. Miao, and D. Zhong, "Optimization extraction of Ganoderma lucidum polysaccharides and its immunity and antioxidant activities," International Journal of Biological Macromolecules, vol. 55, pp. 301-306, 2013.

[8] C. Zhao and Y. He, "Isolation, purification and structural characterization of active polysaccharides from the mycelium of Ganoderma lucidum," Zhong Yao Cai, vol. 25, no. 4, pp. 252-254, 2002.

[9] M. Shi, Z. Zhang, and Y. Yang, "Antioxidant and immunoregulatory activity of Ganoderma lucidum polysaccharide (GLP)," Carbohydrate Polymers, vol. 95, no. 1, pp. 200-206, 2013.

[10] K. Zhu, S. Nie, C. Li et al., "A newly identified polysaccharide from Ganoderma atrum attenuates hyperglycemia and hyperlipidemia," International Journal of Biological Macromolecules, vol. 57, pp. 142-150, 2013.

[11] P. Y. Wang, X. L. Zhu, and Z. B. Lin, "Antitumor and immunomodulatory effects of polysaccharides from broken-spore of Ganoderma lucidum," Frontiers in Pharmacology, vol. 3, 2012.

[12] S. Wang, G. Zheng, S. Tian et al., "Echinacoside improves hematopoietic function in 5-FU-induced myelosuppression mice," Life Sciences, vol. 123, pp. 86-92, 2015.

[13] S. Kojima, K. Takaba, N. Kimoto et al., "Protective effects of glutathione on 5-fluorouracil-induced myelosuppression in mice," Archives of Toxicology, vol. 77, no. 5, pp. 285-290, 2003.

[14] S. Numazawa, K. Sugihara, S. Miyake et al., "Possible involvement of oxidative stress in 5-fluorouracil-mediated myelosuppression in mice," Basic \& Clinical Pharmacology \& Toxicology, vol. 108, no. 1, pp. 40-45, 2011.

[15] Z. Cao, Z. Zhang, Z. Huang et al., "Antitumor and immunomodulatory effects of low-dose 5-FU on hepatoma 22 tumorbearing mice," Oncology Letters, vol. 7, no. 4, pp. 1260-1264, 2014. 
[16] V. J. Picozzi, R. A. Kozarek, and L. W. Traverso, "Interferonbased adjuvant chemoradiation therapy after pancreaticoduodenectomy for pancreatic adenocarcinoma," American Journal of Surgery, vol. 185, no. 5, pp. 476-480, 2003.

[17] Y. Kan, T. Chen, Y. Wu, J. Wu, and J. Wu, “Antioxidant activity of polysaccharide extracted from Ganoderma lucidum using response surface methodology," International Journal of Biological Macromolecules, vol. 72, pp. 151-157, 2015.

[18] M. M. Bradford, "A rapid and sensitive method for the quantitation of microgram quantities of protein utilizing the principle of protein-dye binding," Analytical Biochemistry, vol. 72, pp. 248-254, 1976.

[19] L.-F. Li, H.-B. Liu, Q.-W. Zhang et al., "Comprehensive comparison of polysaccharides from Ganoderma lucidum and $G$. sinense: chemical, antitumor, immunomodulating and gutmicrobiota modulatory properties," Scientific Reports, vol. 8, no. 1, p. 6172, 2018.

[20] A. K. Nowak, B. W. Robinson, and R. A. Lake, "Synergy between chemotherapy and immunotherapy in the treatment of established murine solid tumors," Cancer Research, vol. 63, no. 15, pp. 4490-4496, 2003.

[21] J. Gołąb, R. Zagożdżon, R. Kamiński et al., "Potentiatied antitumor effectiveness of combined chemo-immunotherapy with Interleukin-12 and 5-fluorouracil of L1210 leukemia in vivo," Leukemia, vol. 15, no. 4, pp. 613-620, 2001.

[22] S. Cao, A. B. Troutt, and Y. M. Rustum, "Interleukin 15 protects against toxicity and potentiates antitumor activity of 5fluorouracil alone and in combination with leucovorin in rats bearing colorectal cancer," Cancer Research, vol. 58, no. 8, pp. 1695-1699, 1998.

[23] M. Cheng, Y. Chen, W. Xiao, R. Sun, and Z. Tian, "NK cellbased immunotherapy for malignant diseases," Cellular \& Molecular Immunology, vol. 10, no. 3, pp. 230-252, 2013.

[24] L. L. Lanier, "Up on the tightrope: natural killer cell activation and inhibition," Nature Immunology, vol. 9, no. 5, pp. 495502, 2008.

[25] K. Jiang, B. Zhong, D. L. Gilvary et al., "Pivotal role of phosphoinositide-3 kinase in regulation of cytotoxicity in natural killer cells," Nature Immunology, vol. 1, no. 5, pp. 419425, 2000.

[26] I. Tassi, M. Cella, S. Gilfillan et al., "p110 $\gamma$ and p110 phosphoinositide 3-kinase signaling pathways synergize to control development and functions of murine NK cells," Immunity, vol. 27, no. 2, pp. 214-227, 2007. 


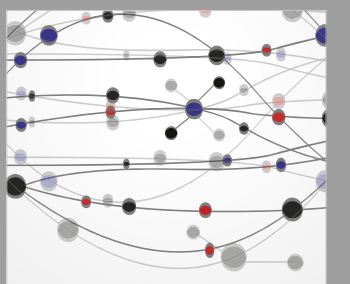

The Scientific World Journal
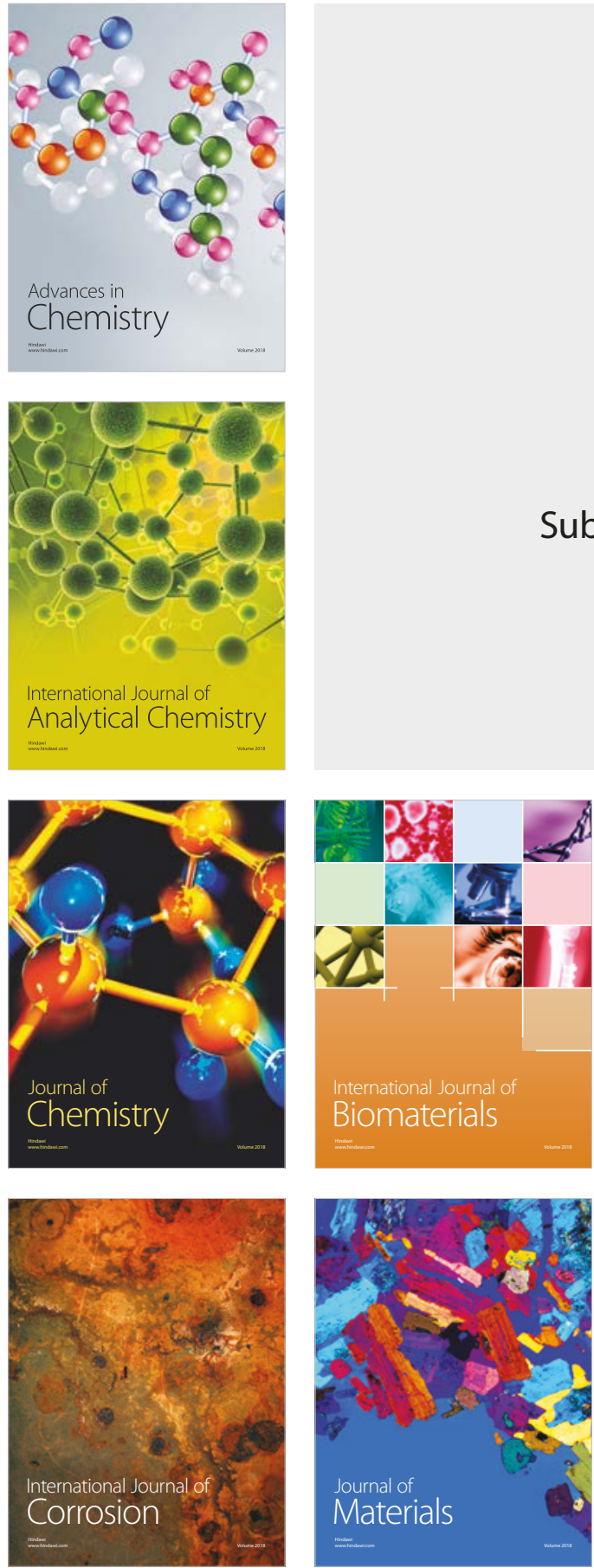

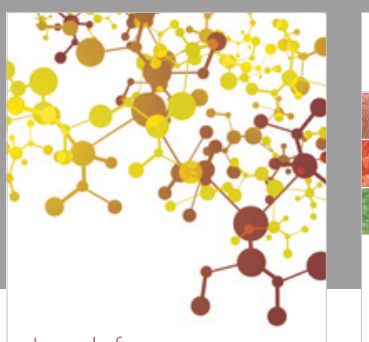

Journal of

Applied Chemistry
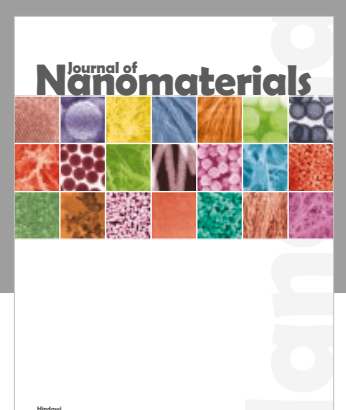

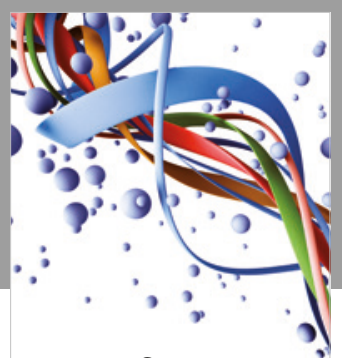

Scientifica

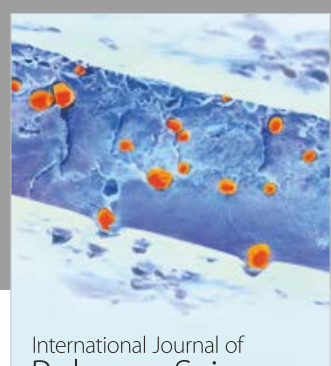

Polymer Science

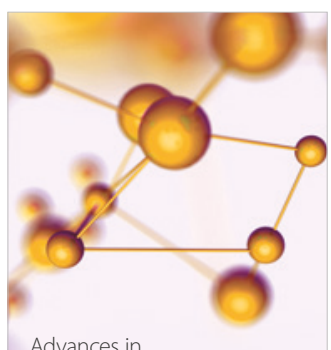

Physical Chemistry
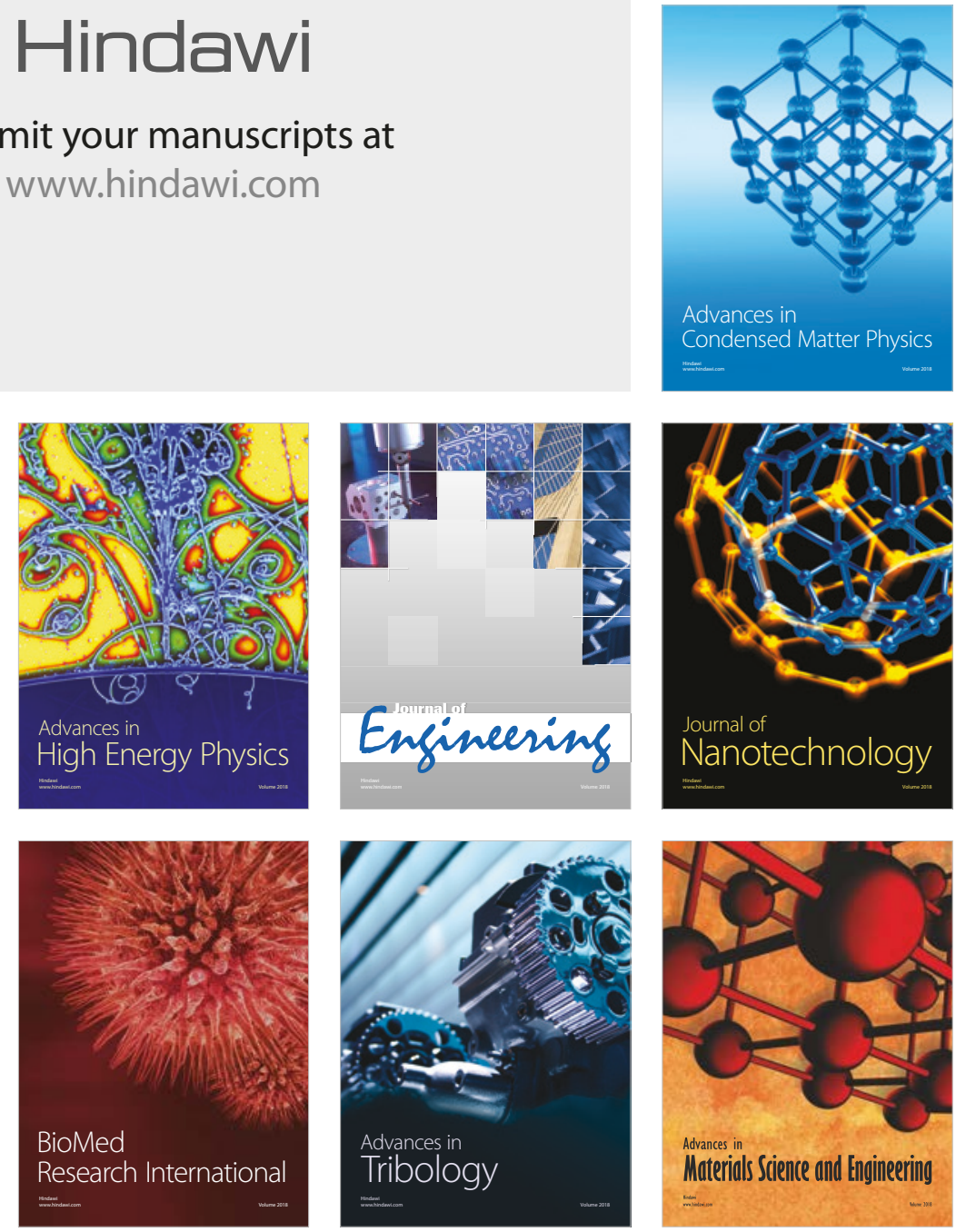